\title{
The urban form in the city of Tulcán, Carchi, Ecuador
}

\author{
Yolanda Tapia ${ }^{1}$, Adolfo Vigil de Insausti ${ }^{1}, M^{a}$ Dolores Montaño ${ }^{2}$
}

${ }^{1}$ Escuela Técnica Superior de Arquitectura. Universitat Politècnica de Valencia, Valencia, Spain

${ }^{2}$ Pontificia Universidad Católica del Ecuador, PUCE. Quito, Ecuador

E-mail: yoly.tapiamora@gmail.com, advide@urb.upv.es,mdmontano@puce.edu.ec

\begin{abstract}
Tulcán, located north in Ecuador is the capital of the Carchi Province. It is a city especially commercial and agricultural whose urban morphology responds to historical, environmental and administrative circumstances since 1851, date on which the "cantonization" takes place, begins the formation of the capital city with an urban structure formed in checkerboard that welcomes the traditional nucleus of the typical city of the ecuadorian highlands. With the development of this city, isolated neighborhoods are born out of the original urban fabric that expand in the territory, following the main road connections, eventually to fill the internal space with a morphology of contrasts, as each neighborhood or new occupations are structured individually without thinking as a city of integral formation. The longitudinal growth of the city was marked from its beginning by the river Bob, to the north-west, and the river Tajamar to the south-east; that keeps the city within natural limits, which also provide certain environmental and landscape benefits; however in the last few decades the city has had a significant growth that threatens an unattended and constantly expanding periphery to these environmental resources. We are facing a heterogeneous city, with problems and possibilities and attending to the idea that the city is an unfinished work, integral and sustainable urban regeneration is the basis for a reordering and a new urban approach. Therefore was proposed to study three strategic lines: the existing city, its internal circuits of connection and the adjacent nature. Establishing initial uses in the city, to occupy the predominant urban void and thus to activate the public space. Restructure mobility, which will strengthen the use of new peripheral road infrastructures to reduce motorized circuits in the interior, thus promoting the use of bicycles and the creation of pedestrian routes. Finally, environmental resources will again have the value of landscape and ecological wealth producing around the city a green infrastructure that contains growth and is a link of this with the countryside.
\end{abstract}

Keywords: Tulcán, Ecuador, urban, landscape, history.

\section{Introduction}

Tulcán is the capital of the Carchi Province and is located at the northern Andes over the interAndean alley of Ecuador, next to the border with Colombia. It's at approximately 3000 meter altitude over sea level.

Its territory has levels with moderate inclinations, medium hills and flat surfaces. Further has a cold equatorial climate of highs altitudes, with a temperature of 10 to $12{ }^{\circ} \mathrm{C}$ that favors to the development of agriculture and livestock activities typical of the zone, besides with the presence of rivers that forms bi national river basins and promotes productive activities. The city includes two urban counties: Gonzales Suarez and Tulcán, distributed longitudinally in the territory. In the last decades there has been a growth of the city in a way that has become distorted and landscapes have been degraded due to urban developments that with their isolated projects consume the soil 
and natural resources only for a commercial purpose. The accelerated transformation of the soil is undoubtedly, an obvious reality that threatens mainly the agricultural landscape, the natural surroundings of the city and therefore the quality of life of its inhabitants.

\section{Methodology}

This investigation begins about a general study of the urban form of Carchi Province's cities, to determine repetitive patterns of urban growth processes.

Thereafter, the investigation centers into a morphological study of the urban form at the Province's capital, Tulcán City, which presents different important singularities that are object of study to understand the Ecuador's highlands cities reality and in that sense, propose urban strategies for a restructuring and improvement of those.

\section{Measurement and analysis}

The urban growth

The urban study development involves an analysis of different aspects that allow the growing of a determined city in a specific area.
This analysis establishes historic and current circumstances into all fields that were or are able to generate growth and the mode by which a city plans it's expansion. It depends of distinct management issues, about politics, administration, social, economic and cultural topics.

The forms of urban growth, should be a result of municipal actions to improve the cities, nevertheless in Carchi Province this kind of actions can't represent an advance because these are individual and secluded acts.

The city wasn't thought like collective, that's why the growth morphology shows a lack of urban planning, that is a basic objective in this topic. Adaptation of new circumstances make necessity of growth, in terms of a response to the vehicle use, bigger edifications and industrial areas, which become into vital aspects of the urban space.

\section{Carchi Province urban growth}

Carchi Province was established in 1880, those days principal activities were livestock and agriculture, so primary environment had experienced a severe change from the beginning of development of the cities; this transformation has evolved over years with the progressive colonization of territory.

Populations take forms from the environment

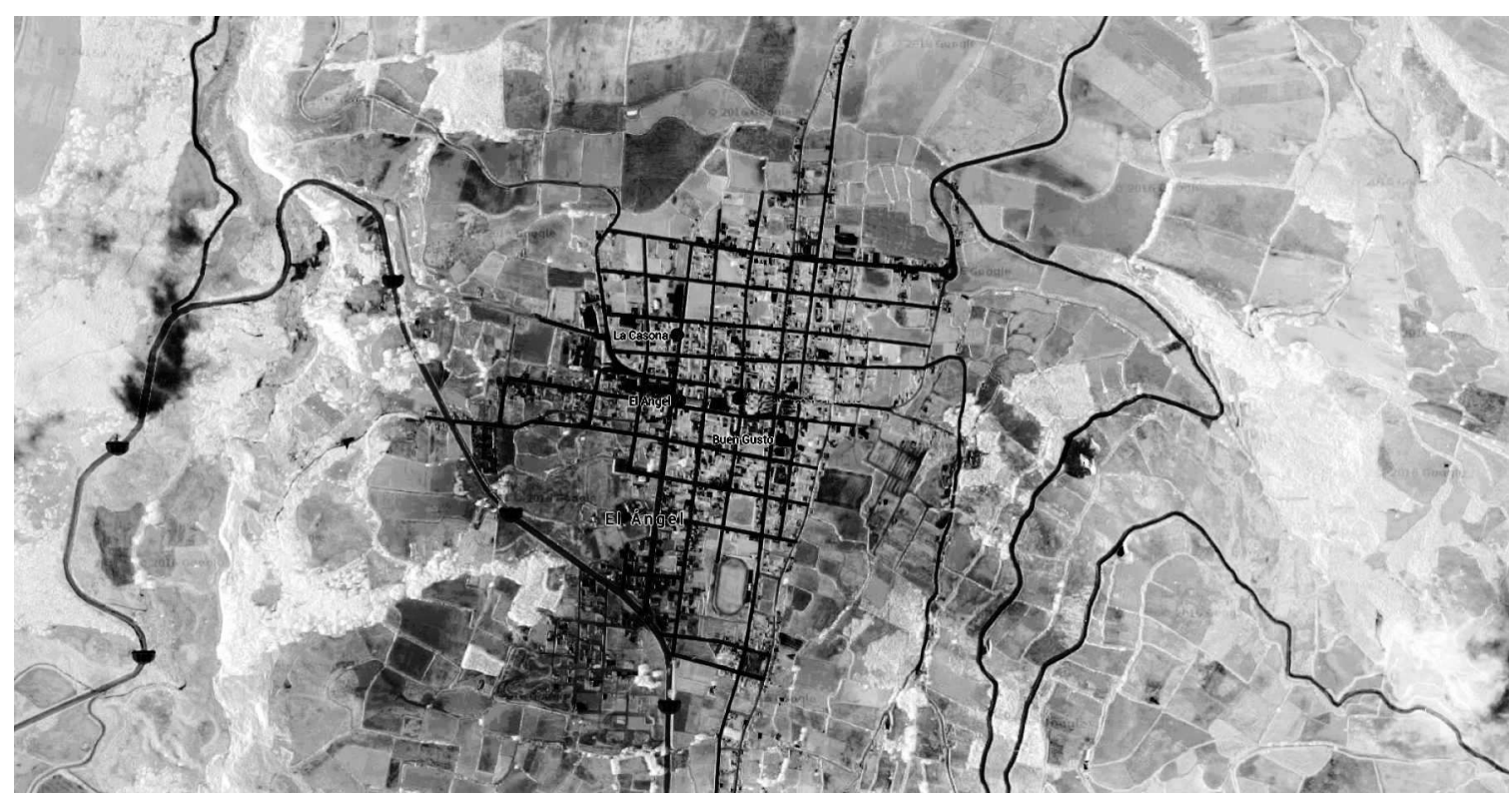

Figure 1.

Aerial view, Ángel city. Carchi 
where they are located, they give rise to various physiognomies in relation with the zone, and the next image shows the agricultural soil like a limit with the Province's cities.

"..Nature is itself an immutable object, nevertheless, history and ethnology show us with all evidence that human eye is the place and medium of an incessant metamorphosis."

Referring to last quote, we are facing a landscape created by humans, where the intrinsic relationship is necessary between this and memory of inhabitants.

Agricultural activity, in the cases of the small populations and large cities, most of times is pretty near, making impossible to identify a limit between city and field; relating in this mode, city activities with agricultural activities without planning, in this point, distinct uses of soil begins to interfere causing incompatibility problems, because every activity has different dynamics that come to be developed in the same area of the city.

Therefore, a new peripheral urban plot begins to be formed, as an element of the consolidated city that is detached and finds place next to the field, making a forced integration that depends of the union of low quality buildings, without an architectural identity and presenting a building typology that not characterizes the city, neither the countryside with the activities and buildings typical of agriculture.

In the studied cities a growth pattern was shown without planning and its inevitable to notice some repetitive conditions like the followings:

-Each city or town has well shaped folk centers, where are the principal endowments and equipment's, also it has road structure and a very clearly building typology, generally this are traditional houses with local materials, wood, clay, bricks, making an landscape integration between the constructions and the environment, this way of proceeding was fundamental in the old cities.

- Recognize the course of the years through the walls of a city is inevitable, once the formation of traditional centers was done, it begins to occupy rustic soil in the most cases, which is transformed on urban ground. Therefore, a new urban typology arises, where the growth takes place in a ground easy to be occupied, not taking into account the developed activity in the mentioned site. At the same time the building typology tends to have less important or quality and the new urban plot has an inexpressive image, in comparison with the essential image that the city had years ago.

- We could deduce that the growth way of the Carchi Province's cities are basic adaptations to the zone topography, these are isolated actuations where city governments determine after the construction, modes to provide basic services, either on industrial areas, familiar residences in a rural zone.

This is how the urban development has been generated in this cities, and probably in all the country (Ecuador), giving as a result more problems than solutions. Big towns, independently of their size, have same growth scheme with different intensities.

The result of this short analysis about the growth pattern is the expansion without planning and with it the appearing of the peripheral city, like this area which expands uncontrolly, increasing problematic dramatically.

Peripheral zone has in its components a very importance agent, the rural soil. It could or couldn't be formed for agricultural activity and then begins to be part of the urban soil, contradicting their use and interposing rural with urban activities; it's worth to say that this kind of activities aren't compatibles.

\section{The urban form of the Tulcán City}

When we speak of urban growth we are used to refer to the great metropolis, this because of their political, social or historical importance, have undergone great transformation processes, the same ones that are now analyzed and many of them are a reference of urbanism and the "contemporary city". Such growth models generally show cities that have spent so much land and the accelerated processes of urbanization have exceeded the limits in relation to the surrounding territory.

In this perspective, it is worth mentioning the minimal or almost inexistent urban interest in the development of smaller cities, which have grown slowly but still have a population increase, an urban expansion and consumption 


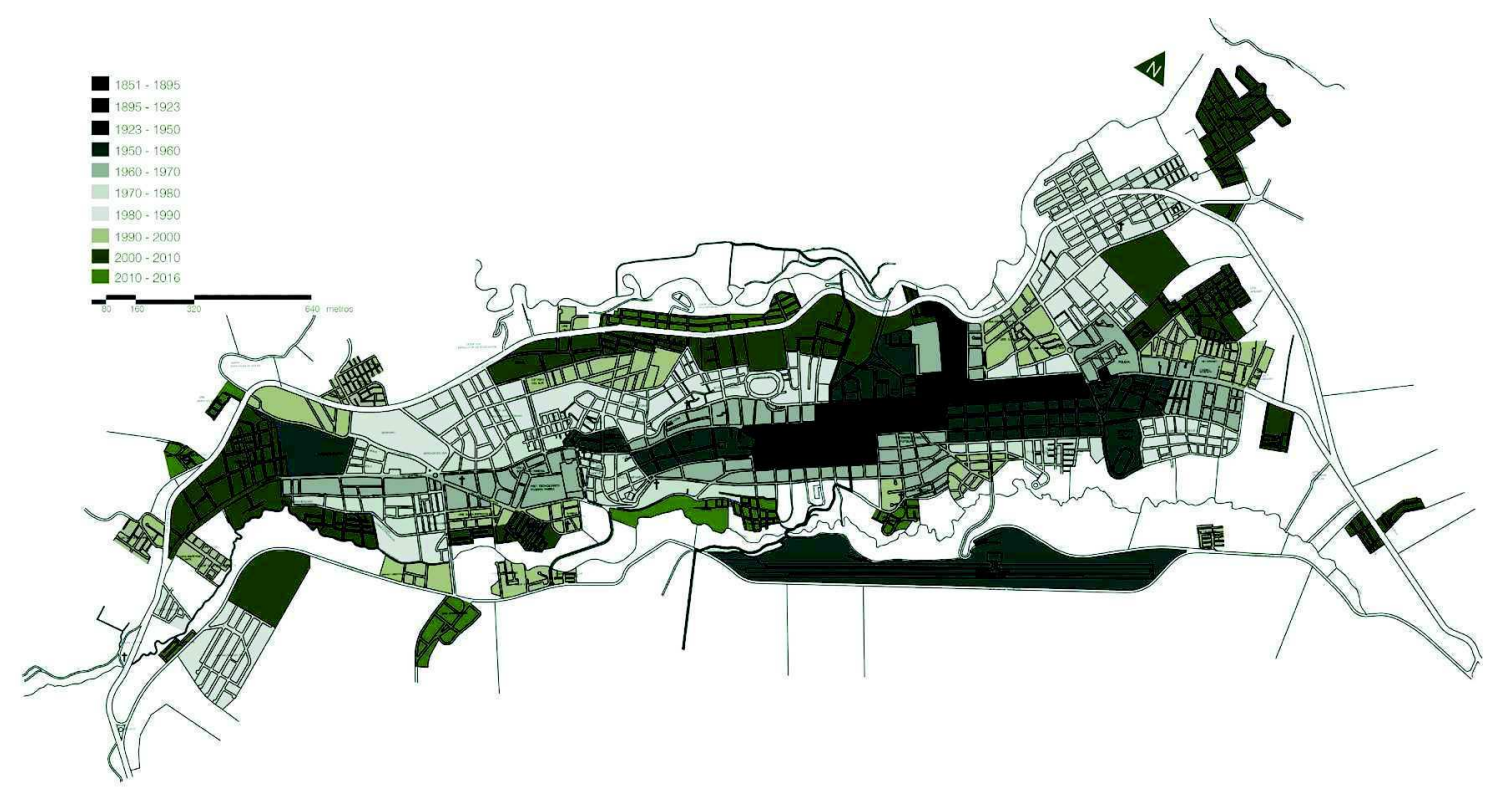

Figure 2.

Urban growth plan. Source. Own elaboration, based on historical data

of land generating as well as happens in big cities, new needs.

The social change and migration of rural inhabitants to cities, regardless of their sizes, is the phenomenon that has caused urban growth. This, add to improvisation and lack of planning gave as result the new growth typologies. Then, if we talk about Barcelona, Paris, Quito or in this case, Tulcán, the periphery is undoubtedly the portion or portions of land do not become part of the cities as such, and remain in ambiguity and lack of urbanistic perspectives.

Rural migration and economic activity have been the main factors for urban growth, however, and compared to other cities in Ecuador, Tulcán has not suffered an exaggerated transformation since its greater conformation. This due to the migration of its young inhabitants, people from 18 to 30 years, sometimes go to other cities because of the lack of opportunities and looking for a higher education many others times. That is the reason it has remained the same in shape and urban structure.

In the last 20 years, the growth and morphological transformation of the city has been greater, taking into account the presence of public and private universities, which has caused a decrease in emigration mentioned above, on the contrary, the increase of educational institutions has changed the conception of the city, because now it welcomes students at a regional level. These considerations set us in context about the reality of the city, where there is a not accelerated but important growth, with isolated projects, where the city is gaining urban area in the immediate agricultural environments, expanding a lot itself, that now, is also necessary to expand the systems of public transportation, networks of basic services, in short, the well-known problematic of the contemporary city.

In general, and with the data obtained, a morphology of a very basic city is shown, it grows by the phenomenon of tension of places of interest. It does not show a study of urban growth model, neither some kind of planning, only isolated decisions based on specific needs. Since the years 2000 to nowadays, the city continues to be established with the same methodology, consuming rural soil and reducing productive activities. At present, there is a greater concern for peripheral areas, resulting from the new processes of urban dispersion from the formed centers.

This type of growth forms the urban structure through points of interest, which have their field of expansion getting together with each other, which refers to the conformation of blocks and neighborhoods in the city, compacting, on one hand, the central city and, in the other one, deriving on the immediate territory. 

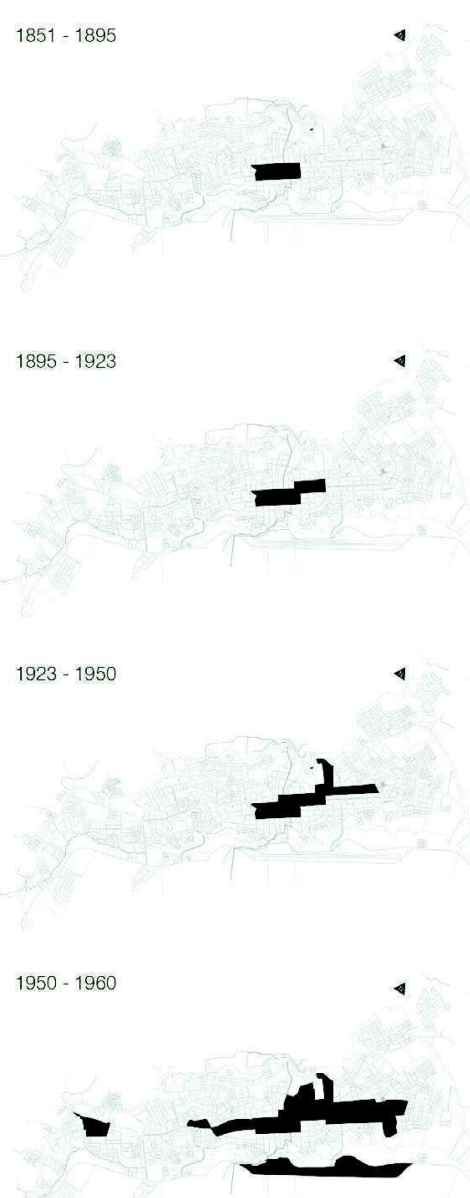

Figure 3.

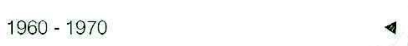

Phases of city growth. Source. Own elaboration, based on historical data.

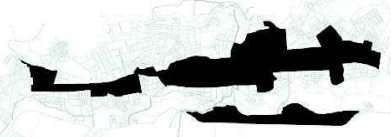

This is how Tulcán, being a small scale city, is currently very complex, because the urban growth, that it has had and continues to have, cause major complications within a small territory. And the absence of planning, or the very superficially work done, is not adapted to the current urban development. The city grows without order, and it is when the concept of peripheries and the reality that they have, is born, especially the problem they present with the rural environment.

In terms of urbanism, the periphery is not something new, in fact, it might be one of the most analyzed, criticized and studied concepts since the middle of last century when most of the world's cities in Europe, America and
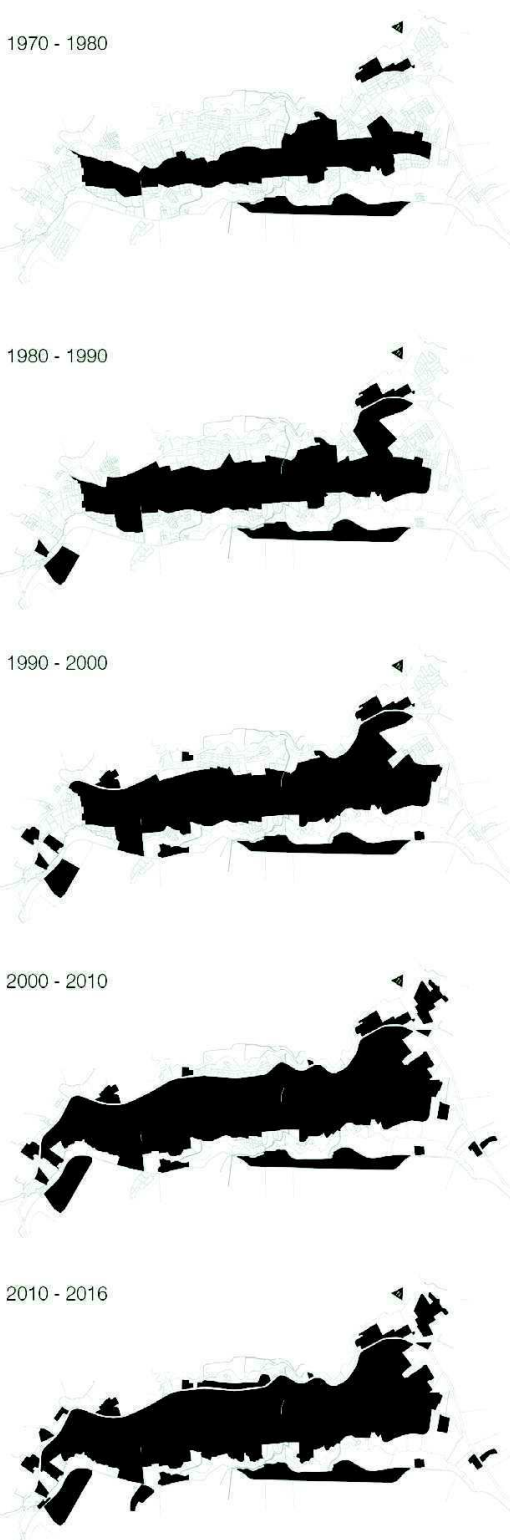

part of Asia, had a powerful development that caused the urban dispersion and with it, the term periphery.

For many authors the periphery is also the suburb, suburban areas, which give name to the dispersed and fragmented city, diffuse city, the city without end. That is to say the term periphery encompasses the contextualisation of contemporary urban realities.

The existence of peripheries in a city demonstrates a social, economic and cultural change that is reflected in its physical form, this is how Tulcán ceased to be a centralized city to possibly become a diffuse city. Since the organized structure of center and compactness is lost with each urban action, therefore it 
is possible to understand as the city and its "parts", what forms the urban totality, where the peripheries are unstable areas in which various structures and ideas of city are merged, they become spaces in which different types of organizations are conjugated, meaning, it brings a new type of urban idea.

"... The peripheral, the space of the periphery, is not the one that awaits its metamorphosis in canonical space, in traditional space. It is not simply a transitory state awaiting its normalization. On the contrary it is a mutation that affects the very foundations of the territory of the urban: another different city ".

Therefore the periphery ceases to be part of the traditional city, however it is what complements it; the new projection of urbanism understands the periphery as a separate system that materializes with the excessive use of soil.

\section{The existent city}

The city has spaces and several characteristics, either in places where the edifications should be maintained for their architectonic and historical value, or well places with new buildings generally without architectonic value and finally the natural spaces in and out the city that allow the connection or the inhabitants with nature.

Thus, the urban landscape is the combination of all of these elements, which makes us understand that the public and private actions establish esthetics and quality of this landscape, in other words, the intervention of the citizen in the city esthetics is related with improvements corresponding to the objects of their properties.

The Tulcán City doesn't count with norms and codes able to allow homogenous actions for treat the different types of building typology, also actions are carried out individually by

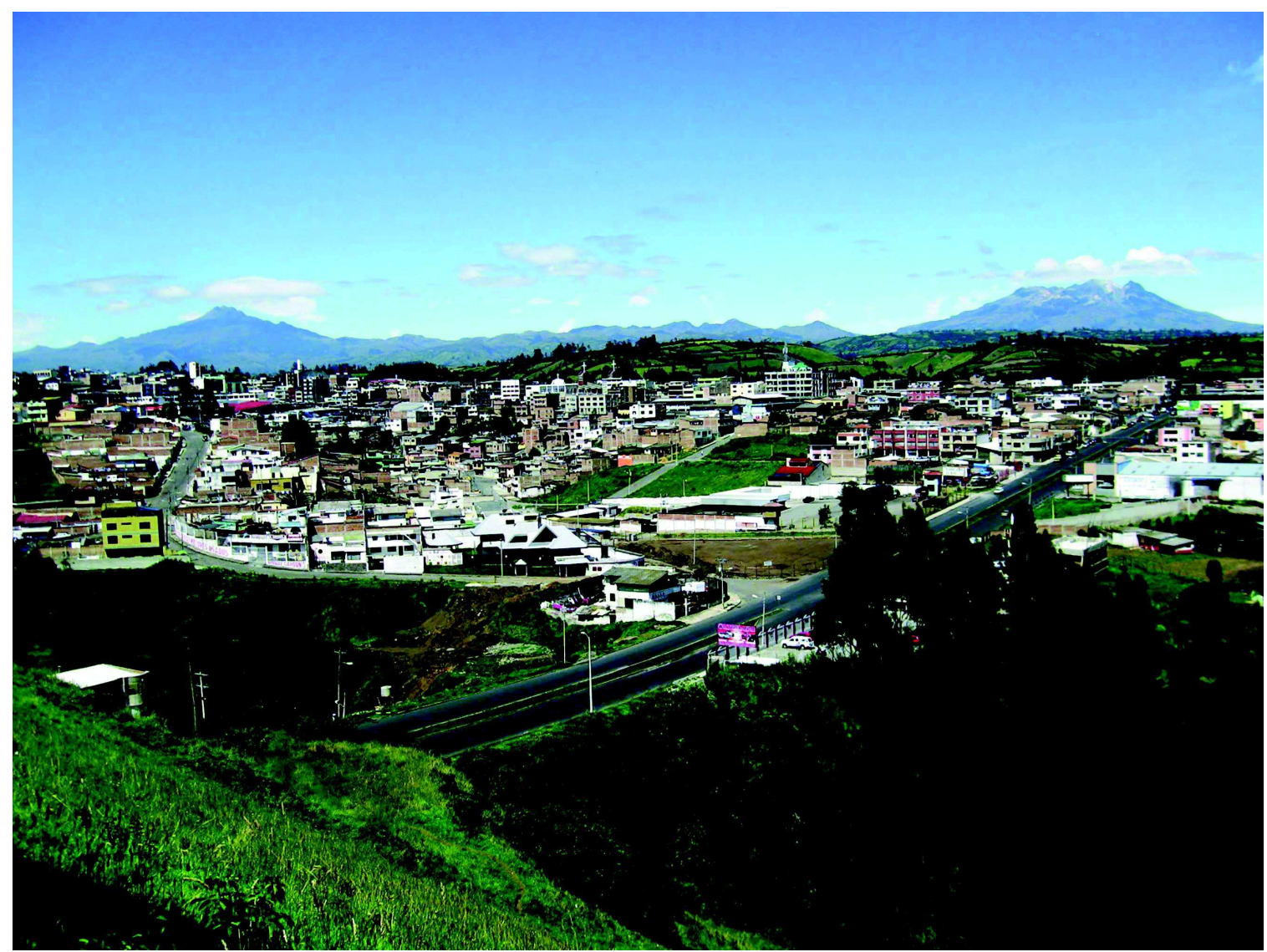

Figure 4.

Tulcán city, Behind, Chiles and Cumbal volcanoes. Source. www.panoramio.com. Bernardo Andrade Tapia 
the owners and in few occasions, organization takes part in the community and neighborhood generating many details, colors, heights principally in houses. Nevertheless, the administrative and governmental buildings "are contemporary" with a scale, form and materials which do not belong to the culture of the city or to the historical profile.

In the periphery neighborhoods, the esthetic has a lower quality because there are some zones where we found damage buildings and a reduced public space, especially in the Bobo and Tajamar riversides, with the corresponding environmental problems; these are factors that negatively affect in the contemplation and protection of these natural spaces.

Every city sector has its own configuration and even an adaptation way to the environment, related with the origin and characteristic of the zone. The perception of Tulcán City's downtown, full of commercial activities, equipment's and a certain "quality" of public spaces result very different to the peripheral neighborhoods, which are disconnected and unattended.

Then, urban landscape is determined by citizens mainly by their quotidian movements related with the city use, according to economics, educational and social activities.

Therefore, the city's downtown can be identified like the most active center in terms of commercial zones; in this sector we can also find the principal administrative buildings around the central square.

What concerns to trade, it's about first floor shops without esthetic, they are like old houses garages or warehouses, where are adapted for sell many kind of products as clothes, food, home appliances and etcetera. These products are shown many times in the sidewalks, generating most part of time interruptions for pedestrians.

In the south of the city, due to the existence of educational and public buildings, recently it has been developed a commercial axis, where soil use is mixed between houses and commercial activities. These considerations, specially mixed use for commerce and dwelling use, generate in the city active sectors full of users with multiple dynamics, leaving the rest of the city into a passive mode where, in many cases, it's unattended because of the absence of activities and users.

\section{Strategy of action on the city}

We must consider the integral rehabilitation of the city's downtown, because there we find buildings that are architecturally acceptable whether they are traditional or modern, many of them underutilized for only commercial purposes. These constructions should serve as a house upper-levels and street commerce in the ground floor, thereby activating public space and the spatial relationship between building and sidewalk in favor of pedestrians; it is said that, the better the quality of public space or outdoor environments, the more activities will be developed in addition to the daily ones. Users will decide to stay, completely changing the idea of a sidewalk of only transit into a place of encounter, rest, relationship and purchases among other human activities.

On other hand, it is about addressing the housing issue, with urban developments that incorporate in its approach equipment that diversify the activities and the use of urban land in addition to thinking of proposals what regenerate the public space and detonate new uses in the city. The new housing concept must also think about neighborhood environments, interpersonal relations, making people care not only of the physical structure but social structure and this way provoking a strengthening of the community and democratic processes that could happen for its administration and maintenance.

Finally, to achieve an urban regeneration in the City of Tulcán, it is necessary to rethink the layout of semi-industrial areas and propose equipment according to the new road infrastructures, provoking active cores, designed in such a way to regenerate the surrounding area, its public space and in general urban life.

\section{Mobility in the city}

Analyzing the urban morphology of Tulcán City, is also necessary to understand the way 
it is structured in matter of road infrastructure, because is determinant at landscaped issue in the territory as much as and in the city.

As was mentioned above and since its inception, Tulcán extends in the territory in a longitudinal way, generating long main and secondary road corridors, among which, we have those that cross internally the city and the roads that surround it, the same can be considered as limits of the city.

Road infrastructures are now the main systems in cities, since they determine their form and their growth, as well as other aspects, that is, they transform the urban and rural landscape, these are elements that provide connectivity between towns, facilitating commercial and social economic relations. Nevertheless the environmental cost is high each time a new path is opened or existing ones are branched out.

This characteristic of dilating the space for mobility and specifically for the automobile is, without a doubt, a peculiarity of the dispersed and contemporary city since its new settlements, distant to the centrality of the city, need to connect physically to achieve the daily activities of its inhabitants.

In Tulcán, mobility is an issue of constant concern, as we are talking about a city that developed without planning and therefore its road and public transport system is the result of this lack of planning; the current municipal administration executes the construction of a fast-track road on the north-west side, connecting the main road nodes to both, the north and south of the city, this action remains on construction and due to speculation and opportunistic actions, new housing cooperatives are created alongside the route that are established in agricultural land.

Finishing the construction of this road, in addition to the existing one on the south-east side with similar characteristics, Tulcán would have a long road ring that would conceptually stop urban growth. However the absence in landscape approaches and the lack of protection zones cancel out all possibilities of the new infrastructures.

In the interior of the city, the issue of mobility is even more complicated, the deficiency of public transport and its poor benefits to users provoke the proliferation of private mobility, filling the streets with vehicles and consequently usurping areas for pedestrians and public space.

\section{Strategy of action on mobility}

Tulcán needs an integral method to regional mobility, perhaps a system of networks that develop and enhance the reasonable management of the territory, the landscape and the city.

The proposal of road networks involves the transformation of territory, the intrusion of external and artificial agents into the natural landscape, is why practical measures are needed for better approaches at the landscape level.

Finally, as was mentioned above, public space is the base of mobility in the city and as such, must provide the necessary amenities to its user, this mode their regeneration is inevitable within a mobility plan. Urban furniture plays an important role from bus stops, signs, places of rest and shade among others, which are aspects that motivate the citizen to walk and avoid the use of private vehicles.

Integral mobility also consists in a radical change in the use of the city, so that within the neighborhoods there must be itineraries that allow the coexistence of different modes of mobility, without any of them becoming vulnerable.

\section{The city and environmental resources}

In the city of Tulcán we find two hydrographic systems, the rivers Bobo and Tajamar, have limited and led the growth of the city. These natural elements, both, water and its basins are threatened by considerable pollution.

It is very remarkable how the city-nature relationship is indefinitely complicated, in this case it could be said "the urban system affects the landscape and the rural environment (the transformations of urbanization, buildings, engineering structures) ...”. In other words, the adaptation of the city to the modern era, produces geomorphological and geodynamic 
changes; mainly the soil and its topography is susceptible to drastic changes, by earthworks for road works or informal construction in many cases, that even alter the slopes necessary for the normal operation of these hydrographic systems. Otherwise, we have pollution caused by drains of nearby dwellings, also other urban waste and chemicals in sectors used as waste lands. This affects especially to the aesthetic of a unplanned city, that is about to reach the limit in matter of use and exploitation land. In an overall view of the current state of the sectors mentioned, it can be stablished that urbanization processes put pressure on the environment, consequently degrading its environmental characteristics and the possible regeneration aids that these could contribute to the city. Moreover it is valid to say that the environment also presses the city as happened with urban growth for example, in addition several cases of landslides could be mentioned, caused by the increase in the flow of rivers, thus demolishing part of buildings, roads and spaces built for the city; that means mutual interactions between the city and the natural elements exist, that is why it is useless to raise a city or parts of it without nature, because sooner or later and in any condition that they could have, a link will be developed that will determine positive or negative changes on both sides.

\section{Strategy for action on environmental resources}

For a coherent planning is necessary to think of the "Structured City" concept analyzed by Agustín Hernández Aja (professor of the UPM in the article that bears the same name), referring to the improvement of the quality of urban life produced by the organization of the existing urban structure which must guarantee mainly social cohesion and care of the environment, for that reason it is imperative to incorporate the concept of sustainability into city planning.

However, currently urban planning, in the city of Tulcán in particular, takes into account a very limited field of information, simple cadastral bases, very basic studies of dispersion of the city, thinking only of the economic development which prevents seeing the city as a whole. Resulting in minimal generation of infrastructure of public space, slight interventions in infrastructure, planning that completely denies the importance of the environment and the improvement of the mobility and transportation system.

Taking this situation into account, it is possible to think of an urban project for Tulcán, that takes care of a multidimensional space in which it is necessary to join systems and articulate infrastructures networks that not only attend the tangible, but, the true needs of the city and the inhabitants. This way an "Urban-ecological Rehabilitation" could be stablished, taking as physical instruments the green spaces of the banks of the rivers Bobo and Tajamar as urban edges that give way to recreation spaces with a high potential landscape and conservation. Also, thinking in the networks or communications to the interior of the city, because the restructuring is not only in the environmental aspect but it is an integral set of actions that formulate a true urban change. Planning therefore must seek urban planning resulting from citizen participation and environmental management.

\section{Conclusion}

This investigation has compiled the necessary information about the Province of Carchi, in subjects about his global structure, like the relation and develop of population cores in the territory and its relation with the surround, concluding that, inside the regional scope or province's territory, Carchi has been structured by an unique national road which has urban sets in development along it, changing a natural surrounding into a series of locations without a previous planning.

With the graphic study of Tulcán, it's concluded that the growth of one city implies an irreversible transformation of the territory and of all the elements which conform it, in this case, the lengthwise growth had been transforming the agricultural space into urban space, and in many cases these don't reach a necessary density, resulting urban voids that leave the productive activity to be absorbed to 
the city without having an utility.

With the study of the morphology of the city of Tulcán, is possible to reveal that this grows in small portions named housing cooperatives, which have been located outside of the limits considerate as urban, creating an unattended periphery, a concept better known as a dysfunctional spaces in the cities. However in the case of Tulcán, for its scale and social and economic conditions, this periphery doesn't have a serious degree of dysfunctionality, giving place to the possibility of a restructuration with the elements that conform it, like dwellings, road infrastructures in small scale and specially with the natural surround which it joins.

Finally, this work gives the opportunity of visualize the physic potentialities that Tulcán has, both at the territorial and local level. The study and the analysis reveals an scenery in which, with the adequate policies and good management, the city could be renewed in all its aspects, reaching a balance that allows an environmental, economic and social sustainability, improving the quality of life of its inhabitants and above all, to recover and maintain the essence of the city as the agricultural landscape.

\section{References}

Beery, B. (1975) 'Consecuencias humanas de la urbanización', Madrid: Pirámide

Gehl, J. (2003) 'La humanización del Espacio Urbano'. Reverté

Hernández, A. (2001) 'La ciudad estructurada', en Boletín CF+S 15 Calidad de vida urbana: variedad, cohesión y medio ambiente. (http://habitat.aq.upm.es/boletin/n15/aaher. html)

Huertas Nadal, D. (2012) 'I making Heterotopías, laboratorio de estrategias urbanas', Vitoria: Universidad Francisco Vitoria

Koolhaas, R. (2006) 'La ciudad genérica'. Gustavo Gili

Lopez de Lucio, R. (2007) 'Construir ciudad en la periferia', Madrid: ETS Arquitectura (UPM) Urbanística y ordenación del territorio
Monclús, F. J. (1998) 'La ciudad dispersa: suburbanización y nuevas periferias'. Centro de cultura contemporánea de Barcelona

Ramirez, J, (2004) 'Líneas en la periferia'. Sabater

Roger, A. (2007) 'Breve tratado del paisaje'. Biblioteca nueva.

Salvador, P. (2003) 'La planificación verde en las ciudades'. Gustavo Gili.

Solá-Morales, M. (1997) 'Las formas del crecimiento urbano', Barcelona:Universitat Politécnica de Catalunya

Urresta, M. (2013) 'Tulcán, Recogiendo huellas'. El conejo 